\title{
Evaluation of bitumen fractional composition depending on the crude oil type and production technology
}

\author{
Miglè Paliukaitè ${ }^{\mathrm{a}}$, Audrius Vaitkus ${ }^{\mathrm{a}}$, Adam Zofka ${ }^{\mathrm{b}}$ \\ ${ }^{a}$ Road Research Institute, Vilnius Gediminas Technical University, Linkmenu st. 28, LT-08217 Vilnius, Lithuania \\ ${ }^{b}$ Road and Bridge Research Institute (IBDiM), ul. Instytutowa 1, 03-302, Warsaw, Poland
}

\begin{abstract}
The present paper focuses on the analysis of the bitumen quality which can be a relevant issue in the performance of road surfacing. Using bitumen from different producers with the same physical characteristics can be significantly different in fractional composition. Crude oil selection and processing play an important role in bitumen properties. Changes in processing and crude sources even within a market may also lead to variability in bitumen fractional composition. The aim of this study is to determine to which extend the type of crude oil and the production technology influence the bitumen fractional composition. Bitumen samples were selected based on the origin crude oil and different producers. In order to obtain information about bitumen chemistry, IATROSCAN MK 6S chromatography was used. The results showed that recommendations of bitumen fractional composition provide a better quality of bitumen according to crude oil type and processing.
\end{abstract}

Keywords: bitumen; bitumen fractional composition; crude oil; chromatography.

\section{Introduction}

Bitumen is a byproduct of the distillation process of the crude oil in refineries. It is an oily, viscous and flammable material. Bitumen properties highly depend on crude oil type and production technology. Production technology is adjusted to the crude oil type: extra heavy, heavy, medium or light. Nowadays heavy oils are processed more frequently than 20-30 years ago, therefore due to the use of different types of crude oils, the distillation residue can differ significantly. Due to the differences in the properties of bitumen residue, asphalt pavement performance can be also different. Refiners tend to characterize crude oils by the type of chains that is most prevalent, i.e. paraffin, naphtenes and aromatics. These types of crude oil characterize the bitumen fractional composition, which has influence on the bitumen physical and mechanical characteristics. The relative amount of asphaltenes, resins, aromatics and saturates depends on the origin of the source crude oil, the refinery treatment and the finishing processes [1-3], [9]. Depending on crude oil sources and marketable products, the main bitumen production process can include atmospheric-vacuum distillation, air-oxidation and additionally solvent extraction and precipitation, chemical treatment and blending of individual crudes [18], [23]. Therefore each of the bitumen differs in their fractional composition due to the nature of their crude oil and the operations involved in its production. The knowledge of crude oil and processing are essential because of established percentage of each bitumen component, which has a high influence to bitumen performance. For instance, asphaltenes are responsible for the presence of structure in bitumen and for their non-Newtonian behavior. They impact on the strength, stiffness and colloidal structure of bitumen. Resins provide adhesion, plasticity and ductility. Saturates and aromatics are responsible for viscosity and fluidity of the bitumen [15], [23].

Bitumen is an organic material, which can be described as a colloidal system consisting of high molecular weight asphaltene micelles dispersed in a lower molecular weight maltenes (resins, aromatics and saturates). Fractional composition of bitumen (asphaltenes, resins, aromatics and saturates) has a large influence on the bitumen performance. Bitumen is widely used in the field of pavement construction due to its excellent mechanical properties, which also depends on bitumen fractional composition [17], [21], [24]. Asphaltenes, resins, aromatics and saturates, mostly called SARA, can be determined by various methods. All methods are based on the difference in solubility of the particular chemical groups of bitumen. The traditional method used to determine bitumen fractional composition is column chromatography, commonly

Corresponding author: Miglè Paliukaitè. E-mail address: migle.paliukaite@vgtu.lt

http://dx.doi.org/10.3846/enviro.2014.162

(C) 2014 The Authors. Published by VGTU Press. This is an open-access article distributed under the terms of the Creative Commons Attribution License, which permits unrestricted use, distribution, and reproduction in any medium, provided the original author and source are credited. 
known as SARA method. The main disadvantage of this method is that it requires a big amount of solvent, long time etc. The High Performance Liquid Chromatography (HPLC) is based on the same approach. Nevertheless using these traditional methods, asphaltenes of the bitumen must be extracted from it before performing the measurement. The new method is based on the Thin-Layer Chromatography with Flame-Ionization Detection (TLC-FID). For separation and quantification, correct use of Iatroscan TLC-FID offers good precision and accuracy, in addition to rapid analysis and low solvent consumption [20], [24]. Using TLC-FID, various percentages of solvents as well as different calculation methods can be used to determine bitumen fractional composition which have a high influence to the results [6], [7], [16], [31].

\subsection{Crude oil types and processing}

Crude oil is a natural mixture of hydrocarbons, generally in the liquid state, that may also include compounds of sulfur, nitrogen, oxygen, metals and other elements. Hydrocarbons are molecules that contain only the elements of carbon and hydrogen. According to the dominant type of hydrocarbon chains, crude oil is classified as: paraffin base, naphthenic base, aromatic base, mixed base [6], [11], [24].

Paraffinic crude oil contains paraffin wax and practically no asphalt or naphthenes. Paraffins are saturated hydrocarbons, straight or branched chains but without any ring structures. The paraffin series of hydrocarbons is characterized by the rule that the carbon atoms are connected by a single bond and the other bonds are saturated with hydrogen atoms. The general formula for paraffins' is $\mathrm{C}_{n} \mathrm{H}_{2 n+2}$ [11]. Typical paraffinic compound is shown in Fig. 1a.

Naphthenic crude oil contains mainly (by volume) naphthenes and other aromatic hydrocarbons completely without paraffin. Naphthenes are defined as saturated hydrocarbons with one or more rings and these hydrocarbons may have one or more paraffinic side chains. It is a closed group of saturated ring of the general formula: $\mathrm{C}_{n} \mathrm{H}_{2 n}$ [11]. Typical naphthenic compound is shown in Fig. 1b.

Aromatic crude oil has an unsaturated ring compound having a basic 6- carbon-atom ring with either a hydrogen atom or a chain joined to each carbon atom. The aromatic group of the general formula is $\mathrm{C}_{n} \mathrm{H}_{2 \mathrm{n}-6}$. The aromatic series of hydrocarbons are chemically and physically very different from the paraffin base and naphthenic base crude oil. Aromatic hydrocarbons contain a benzene ring which is unsaturated but very stable and frequently behaves as a saturated compound [11]. Typical aromatic compound is shown in Fig. 1c.

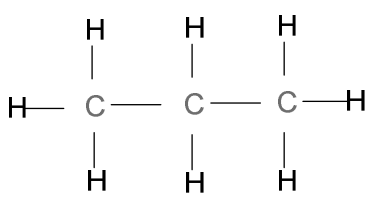

a)

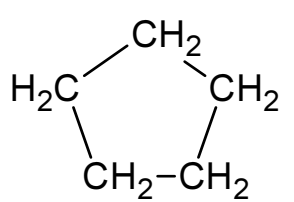

b)

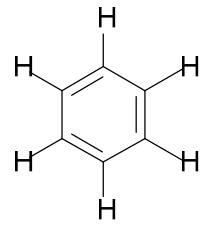

c)

Fig. 1. Molecular structure of different crude oil types: paraffin compounds (a); naphthene compounds (b); aromatic compounds (c)

Generally, paraffin base crude oil is not suitable for the production of bitumen, because of the lack of a sufficient amount of asphaltenes. Nevertheless paraffin crude oil mixed with the naphthenic crude oil can be the basis for the production of bitumen. Aromatic crude oil is more suitable for chemical reagents Therefore, the best crude oil for bitumen production is naphthenic and naphthenic-paraffinic base crude oil.

Another way to classify crude oils is by their density: light, medium, heavy and extra heavy (Table 1). Some crude oils, such as those in the original Pennsylvanian oil fields of the U.S.A., consist mainly of paraffin. Others, such as the heavy Mexican and Venezuelan crude oils, are predominantly naphthenic and rich in bitumen. Russian crude oil is mixed-base (paraffinic and naphthenic), consequently has less asphaltenes and more resins. Heavy crude oils tend to be more aromatic/naphthenic type whereas the lighter crude oils are more paraffinic.

Light crude oil (e.g. Nigeria Bonny) is a low-viscous material with low density. Light crude oil has low viscosity, low specific density and high American Petroleum Institute (API) degree for the high content of light fractions. This type of crude oil will produce higher amount of light fractions, such as gasoline, kerosene, gass oil etc, than a heavy crude oil. Usually light crude oil has a small amount of paraffin. Using this type of crude oil for bitumen production, an oxidation process is required. Comparison of light, heavy and medium crude oils are shown in Table 1.

Heavy/extra heavy crude oil (e.g. Boscan Venezuela) is very viscous material with a high specific density, low API degree. However, this type of crude oil contains high sulphur content, which can be found in organic and inorganic compounds and have a negative influence on bitumen properties. Typically, heavy oil is used in the production of high quality bitumen. Heavy crude oil contains less light fractions and more naphthenic and aromatic hydrocarbons comparing with a light crude oil. Heavy crude oil contains more heteroatoms of nitrogen, sulfur, oxygen and heavy metals. For these reasons, the processing of heavy oil requires special manufacturing techniques to make adequate oil supply and demand. Appropriate selection of crude oil for bitumen production depends on the specific gravity, carbon and sulpfur content, as well as wax and asphaltene content. Composition of different crude oils according to API degree and specific density is shown in Fig. 2. 
As previously mentioned, bitumen properties highly depend on the bitumen fractional composition, most often affected by the structure of asphaltenes and the ratio of asphaltenes versus resins. At the same time bitumen fractional composition depends not only on the crude oil type but also on the producing technology, distillation residual, as in each case the bitumen fractional composition can be different. There are many kinds of crude oil but only a few of them are suitable for the production of bitumen [34].

Bitumen is a complex chemical mixture that may be manufactured to yield very different physical and chemical attributes. Bitumen is most commonly produced through refining of crude oil using atmospheric-vacuum distillation and oxidation process. Oxidized bitumen is made by passing air through bitumen at elevated temperatures in order to meet the specific requirements, i.e. stiffen it and/or increase the softening point [34]. In this process, chemical reactions change the chemistry of the bitumen while increasing the material's average molecular weight [15], [34]. In order to produce high quality bitumen from heavy or extra heavy oil modern oil refineries use special equipment for processing of bitumen, i.e. they use only atmosferic-vacuum distillation process [35].

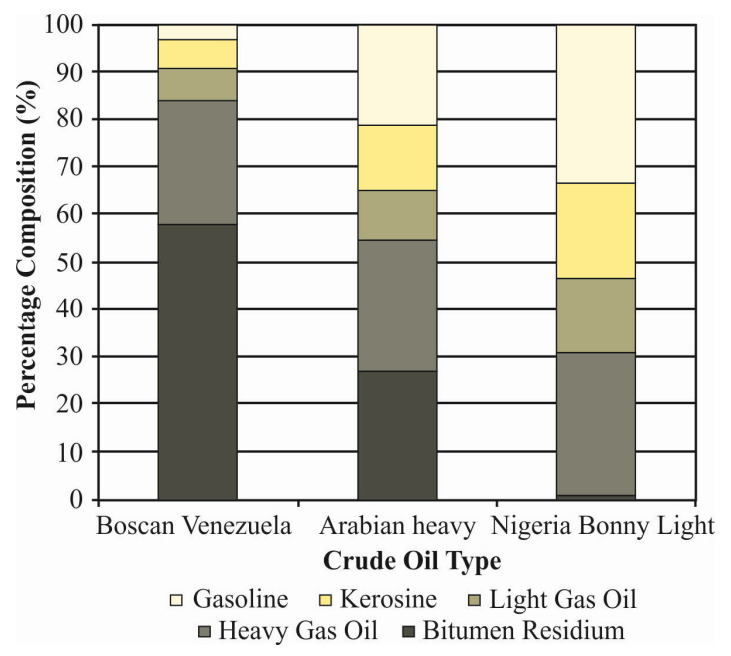

Fig. 2. Composition of different types of crude oil [5]

Table 1. Comparison of different types of crude oil according to API degree and specific density [34]

\begin{tabular}{lll}
\hline Crude oil & API degree & Specific density \\
\hline Light & $>31,1^{\circ}$ & $<870 \mathrm{~kg} / \mathrm{m}^{3}$ \\
\hline Medium & $22,3-31,1^{\circ}$ & $870-920 \mathrm{~kg} / \mathrm{m}^{3}$ \\
\hline Heavy & $<22,3^{\circ}$ & $920-1000 \mathrm{~kg} / \mathrm{m}^{3}$ \\
\hline Extra heavy & $<10^{\circ}$ & $>1000 \mathrm{~kg} / \mathrm{m}^{3}$ \\
\hline
\end{tabular}

\subsection{Characterization of SARA components existing in the bitumen}

Thin layer chromatograph technique uses the Flame Ionization Detector (FID) in order to determine bitumen fractional composition. The samples are developed on a thin layer quarts rod "Chromarod" designed for IATROSCAN system. TLCFID is capable to determine bitumen SARA components, i.e. asphaltenes, resins, aromatics and saturates, much more rapidly comparing with previously mentioned methods. Fractional composition of bitumen expressed by molecular structure is shown in Fig. 3. The FID signal of bitumen fractions is shown in Fig. 4.

Asphaltenes are high molecular weight (800-3500 g/mol), $n$-heptane insoluble black or brown amorphous solids containing, in addition to carbon and hydrogen, some nitrogen, sulphur and oxygen. Asphaltens are the main component to bitumen fractional composition and constitute 5 to $25 \%$ of the bitumen [4], [28]. Their elemental analysis is stable from one bitumen to the other with $\mathrm{H} / \mathrm{C}$ ratio between 0.98 and 1.56 . Their solubility parameter ranges between 17.6 and $21.7 \mathrm{MPa}$ and their density at $20{ }^{\circ} \mathrm{C}$ is close to $1.15 \mathrm{~g} / \mathrm{cm}^{3}$ [ [4-14].

Resins are chemically similar to the asphaltenes and they are a transition from oils to asphaltenes. They are semisolid or solid at room temperature, fluid when heated and brittle when cold. Resins, also called polar aromatics, can be numerous as aromatics (30-45 wt.\%) [4]. Their molecular weight ranges from 300 to 2000, solubility parameter lies between 18.5 and $20 \mathrm{MPa}^{0.5}[28]$ and their density at $20{ }^{\circ} \mathrm{C}$ is close to $1.07 \mathrm{~g} / \mathrm{cm} 3[4]$.

Aromatics (often called aromatics/naphthenics) are a black, highly viscous liquid. The fraction consists of ring structures and forms the bulk of bitumen. Aromatics are the most abundant constituents of a bitumen together with the resins, since they amount for 30-45 wt.\% of the total bitumen [4]. A number-average molecular weight of order $800 \mathrm{~g} / \mathrm{mol}$. Their solubility parameter is between 17 and $18.5 \mathrm{MPa}^{0.5}$ [28] and their density at $20{ }^{\circ} \mathrm{C}$ close but less than $1 \mathrm{~g} / \mathrm{cm} 3$ [4].

Saturates, when isolated, are a clear (water white) liquid of medium viscosity and act as a diluting medium in bitumen. This fraction has lowest molecular weight and consists of straight and branched chain structures. Saturates usually amount 
for 5-15 wt.\% of a paving grade bitumen [4]. Their $\mathrm{H} / \mathrm{C}$ ratio is close to 2, with only traces of hetero atoms [35]. Their number-average molecular weight is around $600 \mathrm{~g} / \mathrm{mol}$ and they are mainly aliphatic. Very few polar atoms or aromatic rings are present. Their solubility parameter is between 15 and $17 \mathrm{MPa}^{0.5}[28]$ and their density at $20{ }^{\circ} \mathrm{C}$ is around $0.9 \mathrm{~g} / \mathrm{cm}^{3}$ [4].

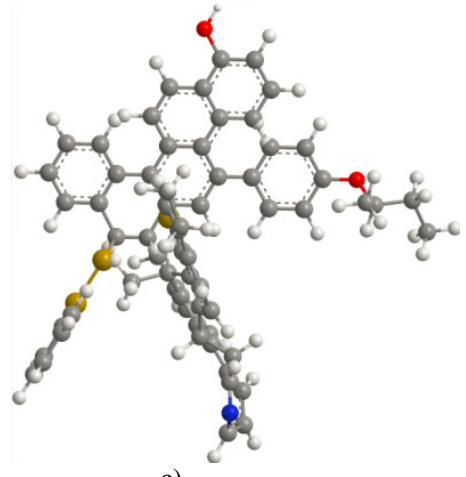

a)

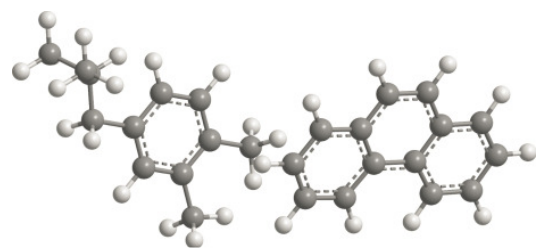

c)

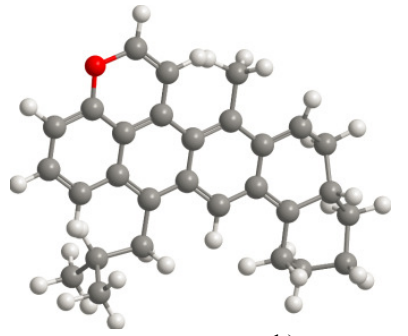

b)

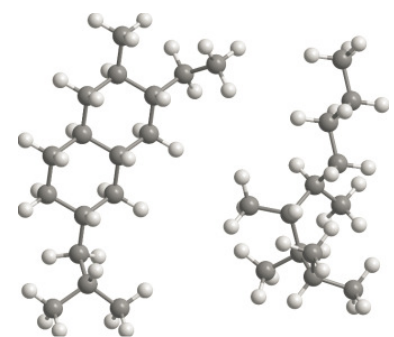

d)

Fig. 3. Bitumen fractional composition expressed by molecular structure: asphaltenes (a); resins (b); aromatics (c); saturates (d)

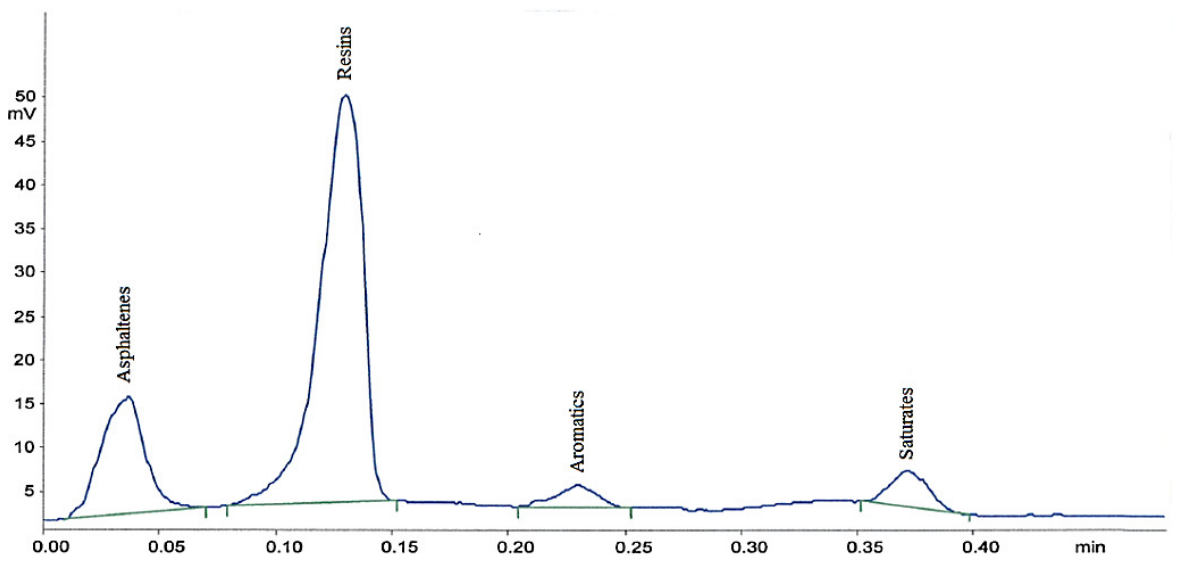

Fig. 4. The FID signal of bitumen fractions

Bitumen is a colloidal system, which consists of maltenes (resins, aromatics, saturates) and asphaltenes. The most important components of bitumen colloidal system are asphaltenes, which quantity and the interaction with the resins, aromatics and saturates influence bitumen rheological properties. In order to determine an interaction between bitumen fractional composition and physical, mechanical properties, one single parameter Gaestel index $\left(I_{\mathrm{c}}\right)$ is used. The Gaestel Index [8], [12], [22], [27] was developed to indicate the colloidal stability of bitumen and is calculated as follows:

$$
I_{C}=\frac{\text { Saturates }+ \text { Asphaltenes }}{\text { Resins }+ \text { Aromatics }}
$$

Saturates and asphaltenes are the lowest and highest polarity components of a bitumen, respectively, and the solubility of the asphaltenes in a colloidal system is enhanced by the presence of intermediate polarity species such as aromatics and resins. Thus, the higher the Gaestel Index, the less stable the overall system is. This index was developed to indicate colloidal stability of bitumen. The primary fractional parameter of importance is most likely the asphaltenes content. Colloidal system of bitumen is unstable when Gaestel index is from 0,5 till 2,7. Requirements of colloidal instability index are given in Table 2. Recommendations of bitumen fractional composition in different countries are shown in Table 3. 
Table 2. Requirements of colloidal instability index [8, 19]

\begin{tabular}{llll}
\hline$I_{\mathrm{c}}$ & $\mathbf{0 , 5 - 2 , 7}$ & $I_{\mathrm{c}}>\mathbf{0 , 5}$ & $I_{\mathrm{c}}<\mathbf{0 , 2 2}$ \\
\hline State of bitumen & Colloidal system is not stable & Bitumen becomes more harder & Bitumen becomes more softer \\
\hline
\end{tabular}

Table 3. Recommendations of bitumen fractional composition in different countries [4], [6], [25], [32], [33].

\begin{tabular}{lllll}
\hline State & \multicolumn{2}{l}{ Bitumen fractional composition } & & \\
\hline & Asphaltenes, $\%$ & Resins, $\%$ & Aromatics, $\%$ & Saturates, \% \\
\hline JAV & $5-25$ & $15-25$ & $45-60$ & $5-20$ \\
\hline Great Britan & $5-25$ & $15-25$ & $40-65$ & $5-20$ \\
\hline Romania & $15-35$ & $18-48$ & $40-60$ & $5-15$ \\
\hline Spain & $5-20$ & $30-45$ & $30-45$ & \\
\hline Russian & $10-25$ & $20-40$ & $40-60$ & \\
\hline Belarus & $19-21$ & $32-34$ & $45-49$ & \\
\hline
\end{tabular}

\subsection{The experimental research and analysis of bitumen fractional composition}

The aim of the experimental research was to investigate bitumen fractional composition depending on the producer and the different crude oil type. Five bitumens of the same penetration grade (50/70) coming from different producers were coded as: A, B, C, D, E. All producers have used Russian crude oil, except for the producer C - Venezuelan crude oil.

The TLC-FID IATROSCAN was used to separate bitumen into: saturates, aromatics, resins, and asphaltenes. Bitumen solutions were prepared in toluene, and $1 \mu 1$ of the sample solution was spotted on Chromarods. In this study, the TLC-FID was conducted on Iatroscan MK-6s analyzer. The samples were dissolved in toluene with concentration of $1 \%(\mathrm{w} / \mathrm{v})$. After Chromarods were cleaned and activated, $1 \mu \mathrm{L}$ of sample solution was spotted on each Chromarod using a spotter. The separation was performed using a three-stage process. The first development was in n-heptane (100\%), second stage in toluene $(100 \%)$, and the last development was in dichloromethane/methanol ( $95 / 5$ by volume). Finally, the Chromarods were scanned in the TLC-FID analyzer. For each sample, 7 Chromarods were tested and the average value of the seven readings was taken as the result.

The analysis of bitumen 50/70 fractional composition showed that the most conspicuous bitumen is from producer $\mathrm{C}$, containing a low content of resins and a large amount of aromatic hydrocarbons, which finally will settle to asphaltens. It is based on the crude oil type, which is naphthenic with a high content of organic sulphur. Crude oil containing sulfur in organic compounds has less resistance to oxidation in short term aging.

Moreover, resins play an important role in the stability of asphaltenes as the asphaltenes are dispersed in them. Results show that the highest content of resins is found in bitumen from producer B. This kind of biutmen is from paraffinicnaphthenic base crude oil (Russian) which contains more paraffin comparing to Venezuelan crude oil.

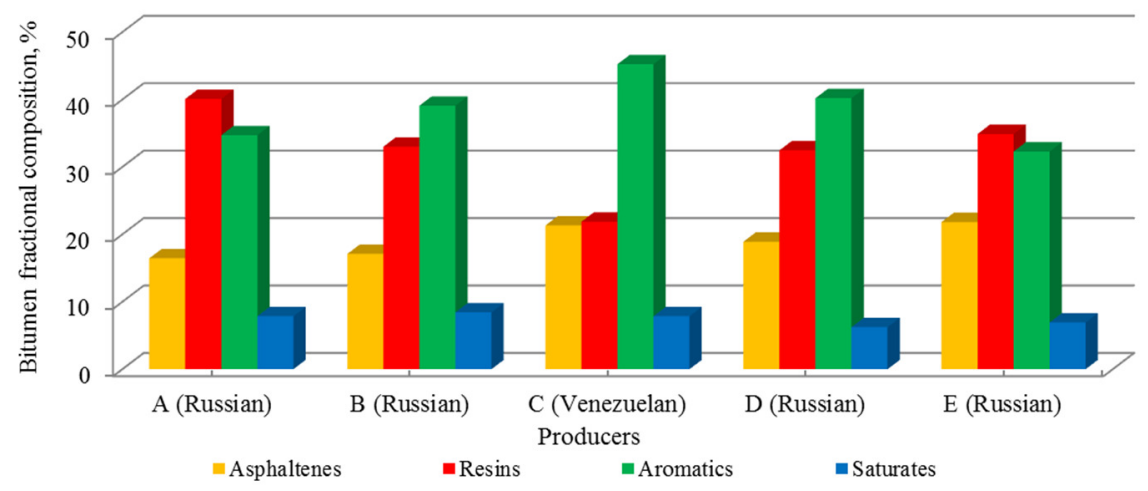

Fig. 5. Bitumen fractional composition from different producers

Many studies have been done to determine the paraffin influence on the bitumen properties. During this experimental research it was possible to determine only saturates, which consists of paraffin and other compounds. The presence of paraffin in bitumen causes a physical hardening effect at lower temperatures, which encourages the formation of cracks [10]. Using bitumen composed of high percentage of paraffin, asphalt mixtures tended to show a higher fracture temperature. Nevertheless, the effect of paraffin on bitumen quality and asphalt mixture performance depends on many factors, such as a precise fractional composition of the bitumen and particularly the nature of the wax temperature [29]. Bitumen fractional composition from different producers is shown in Fig. 5. According to experimental research and other long term scientific 
studies, some of the countries have their own requirements of bitumen fractional composition. Recommended bitumen fractional composition from the experimental research is presented in Fig. 6.

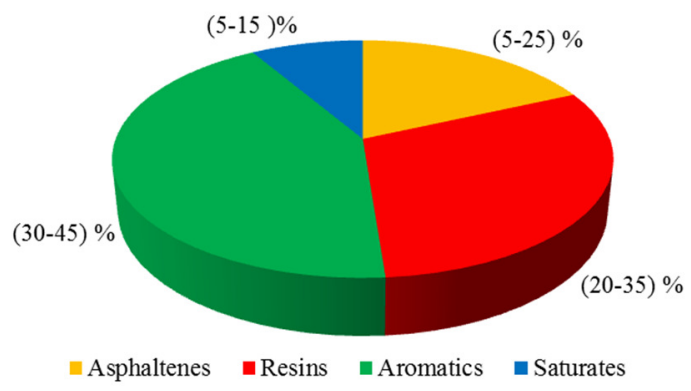

Fig. 6. Recommended bitumen fractional composition from the experimental research

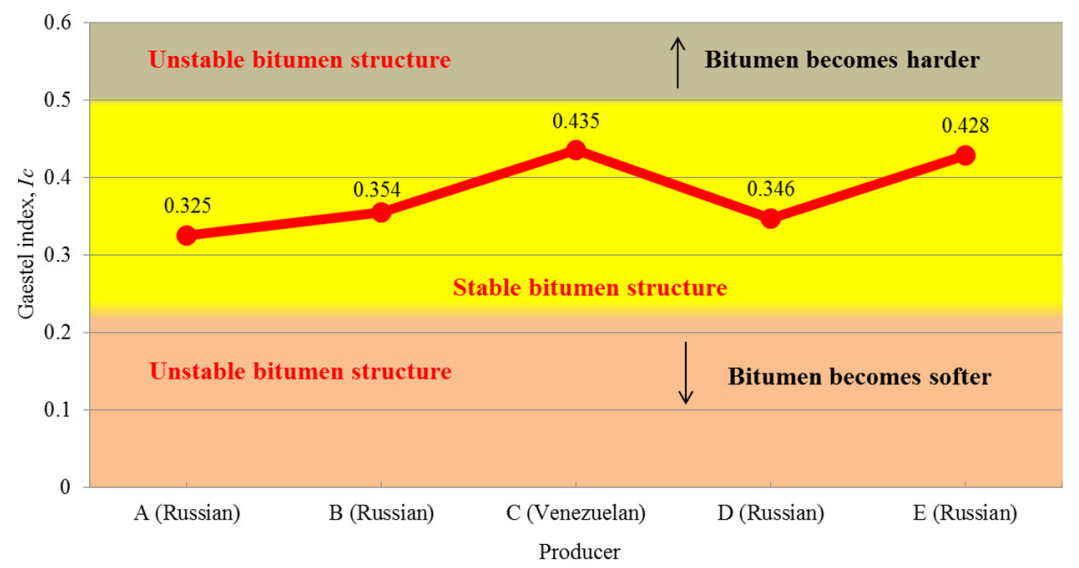

Fig. 7. Bitumen colloidal stability

Figure 7 describes the relationship between the Gaestel index $\left(I_{\mathrm{c}}\right)$ and five bitumens from different producers. There is an optimal range of the $I_{\mathrm{c}}$ values beyond which the colloidal stability decreases. The index is therefore very helpful in comparing the stability of binder samples. Colloidal stability of bitumen shows an increasing trend with an increased level of asphaltens. The data in Fig. 7 shows that colloidal system of all bitumens is stable, emphasizing that bitumen from producers $\mathrm{C}$ and $\mathrm{D}$ tend to be more harder than other bitumens.

\section{Conclusion}

Crude oil type and processing can cause significant changes in bitumen fractional composition. Venezuelan crude oil is a naphthenic type of crude. This means a very high content of bitumen and a high acid rate. Russian crude oil is paraffinicnaphthenic type of crude with higher content of paraffin, so in order to meet requirements of bitumen physical properties, oxidation process is needed.

All of the investigated bitumens show a satisfactory stability, although the bitumens obtained from paraffin-naphthenic crude oil display slightly lower values of the colloidal stability parameter. This can be attributed to a greater aggregation of asphaltene micelles and lower resins to asphaltenes ratio in these bitumens. A good knowledge of the fractional composition of bitumen and understanding of their colloidal stability can provide useful information about bitumen quality and performance in asphalt pavements.

Recommendations of bitumen fractional composition could provide a better quality of bitumen, taking into account not only bitumen physical and mechanical properties but also analysing the potential reasons for the changes in the bitumen characteristics during the pavement service life. The primary fractional parameter of importance is the asphaltenes content. With greater amount of aromatics, adhesion properties are improved between bitumen and minerals. At higher asphaltenes and resins content, increases the dynamic and kinematic viscosity and brittleness temperature. To achieve a high quality of bitumen, according to this experimental study, fractional composition is recommended as asphaltenes 5-25\%, resins 20 $35 \%$, aromatics $30-45 \%$ and saturates $5-15 \%$. 


\section{References}

[1] Allen, R. G.; Little, D. N.; Bhasin, A.; Glover, Ch. J. 2014. The effects of chemical composition on asphalt microstructure and their association to pavement performance, International Journal of Pavement Engineering 15(1): 9-22. http://dx.doi.org/10.1080/10298436.2013.836192

[2] Anderson, D. A.; Dukatz, E. L.; Rosenberger, J. L. 1983. Properties of Asphalt Cement and Asphaltic Concrete, Proc. Assoc. Asph. Pav. Technol. 52: 291-324.

[3] Barre, L.; Espinat, D.; Rosenberg, E.; Scarsella, M. 1997. Colloidal structure of heavy crudes and asphaltenes. Oil\&Gas Sci. Technol., IFP, 52:161175. http://dx.doi.org/10.2516/ogst:1997015

[4] Corbett, L. W. 1969. Composition of asphalt based on generic fractionation, using solvent deasphaltening, elution-adsorption chromatography and densimetric characterization, Anal Chem 41: 576-579. http://dx.doi.org/10.1021/ac60273a004

[5] Corbett, L. W.; Urban, R. 2005. Asphalt and Bitumen. Wiley-VCH Verlag GmbH \& Co. KGaA, Weinheim.

[6] Lesueur, D. 2009. The colloidal structure of bitumen: Consequences on the rheology and on the mechanisms of bitumen modification, Advances in Colloid and Interface Science 145: 42-82. http://dx.doi.org/10.1016/j.cis.2008.08.011

[7] Ecker, A. 2001. The application of Iatroscan-technique for analysis of bitumen, Petrol Coal 43: 51-53.

[8] Gaestel, C. R.; Smadja, K. A. 1971. Lamminan Contribution à la connaissance des propriétés des bitumes routiers Revue Générale des Routes et Aérodromes, 466: 85-97.

[9] Gawel, I. 1993. Relationship between the production method and the properties and composition of bitumens, in Proceedings of the 5th Eurobitume Congress, Stockholm, Sweden, 175.

[10] Hesp, S. A. M.; Iliuta, S.; Shirokoff, J. W. 2007. Reversible aging in asphalt binders, Energy and Fuels 21(2): 1112-1121.

http://dx.doi.org/10.1021/ef060463b

[11] Hsu, C. S.; Robinson, P. R. 2006. Practical Advances in Petroleum Processing Volume 1. 2006 Springer Science Business Media, Inc. http://dx.doi.org/10.1007/978-0-387-25789-1

[12] Yang, P.; Cong, Q.; Liao, K. 2003. Application of Solubility Parameter Theory in Evaluating the Aging Resistance of Paving Asphalts, Petroleum Science and Technology 21(11-12): 1843-1850. http://dx.doi.org/10.1081/LFT-120024565

[13] Jiang, Ch.; Larter, S. R.; Noke, K. J.; Snowdon, L. R. 2008. TLC-FID (Iatroscan) analysis of heavy oil and tar sand samples, Organic Geochemistry

39: 1210-1214. http://dx.doi.org/10.1016/j.orggeochem.2008.01.013

[14] Lian, H.; Lin, J.R.; Yen, T. F. 1994. Peptization studies of asphaltene and solubility parameter spectra, Fuel 73: 423-428. http://dx.doi.org/10.1016/0016-2361(94)90097-3

[15] Leiva-Villacorta; F.; Villegas-Villegas, R. E.; Aguiar-Moya, J. P.; Salazar-Delgado, J.; Salazar, L. G. L. 2013. Effect of aging rheological, chemical and thermodynamic properties of asphalt components, in the 93rd Annual Meeting of the Transportation Research Board Submitted on August 1.

[16] Leroy, G. 1989. Bitumen analysis by thin layer chromatography (IATROSCAN), in Proc. 4th Eurobitume Congress, Madrid; 166-170.

[17] Lu, X. H.; Isacsson, U. 2000. Artificial aging of polymer modified bitumens, J. Appl. Polym. Sci. 76: 1811-1824.

[18] Nelson, W. L. 1958. Petroleum Refinery Engineering, 4th ed. New York: McGraw-Hill.

[19] Oliver, J. W. H. 2012. Changes in the Chemical Composition of Australian Bitumens, Road Materials and Pavement Design 10(3): 569-586. http://dx.doi.org/10.1080/14680629.2009.9690214

[20] Orea, M; Alberdi, M.; Ruggiero, A.; Colaiocco, S. 2002. Alternative calibration and standartization procedure of Iatroscan TLC-FID for SARA hydrocarbons class wuantification: application to tar-mat zone indentification, Fuel Chemistry Division Preprints $47(2)$ : 652.

[21] Ouyang, C. F.; Wang, S. F.; Zhang, Y.; Zhang, Y. X. 2006. Improving the aging resistance of styrene-butadiene-styrene tri-block copolymer modified asphalt by addition of antioxidants, Polym. Degrad. Stabil. 91: 795-804. http://dx.doi.org/10.1016/j.polymdegradstab.2005.06.009

[22] Oyekunle, L. O. 2006. Certain relationships between chemical composition and properties of petroleum asphalts from different origin. Oil \& Gas Science and Technology Revue 61: 433-441. http://dx.doi.org/10.2516/ogst:2006043a

[23] Oyekunle, L. O. 2007. Influence of Chemical Composition on the Physical Characteristics of Paving Asphalts, Petroleum Science and Technology 25: 1401-1414. ISSN: 1091-6466 print/1532-2459online. http://dx.doi.org/10.1080/10916460500528854

[24] Petersen, J. C. 1984. Chemical Composition of Asphalt as Related to Asphalt Durability: State of Art, TRR999, Transportation Research Board, Washington D.C., pp 13-30.

[25] Read, J.; Whiteoak, D. 2003.The Shell Bitumen Handbook. Fifth edition.

[26] Redelius, G. 2006. The structure of asphaltenes in bitumen. Road Materials and Pavement Design.EATA, pp. $143-162$.

[27] Siddiqui, M. N.; Ali, M. F. 1999. Studies on the aging behavior of the Arabian asphalts, Fuel 78: 1005-1015. http://dx.doi.org/10.1016/S00162361(99)00018-6

[28] Speight, J. G. 1999. The Chemistry and Technology of Petroleum. 3rd. Ed. New-York: Marcel Dekke r; 1999.

[29] Schmets, A.; Kringosa, N.; Pauli, T.; Redelius, P.; Scarpasa, T. 2010. On the existence of wax-induced phase separation in bitumen, International Journal of Pavement Engineering 11(6): 555-563. http://dx. doi.org/10.1080/10298436.2010.488730

[30] THE NEW ENCYCLOPEDIA BRITANNICA 1986:99, http://www.eb.com.

[31] Teugels, W.; Zwijsen M. 1991. Analysis of the generic composition. Appraisal of the Iatroscan method, in International Symposium Chemistry of Bitumen. June 5-8, 1991. Roma (Italy).

[32] The Asphalt Binder Handbook. 2011.

[33] Колбановская, А. С.; Михайлов, В. В. Дорожные битумы. Москва: Транспорт, 1973. 264 с.

[33] Stelea, S. 2007. Present Trends in Improving Quality of Pavement Bitumen. Article No. 46, Intersections/Intersecţii 4(4), "Construction Materials".

[34] The Bitumen Industry - The Global Perspective 2011. Production, chemistry, use, specification and occupation exposure. Second adition.

[35] Homayuni, F.; Hamidi, A. A.; Vatani, A. 2012. An Experimental Investigation of Viscosity Reduction for Pipeline Transportation of Heavy and ExtraHeavy Crude Oils, Petroleum Science and Technology 30: 1946-1952. http://dx.doi.org/10.1080/10916461003681646

[36] Claudy, P.; Létoffé, J. M.; King, G. N.; Planche, J. P. 1992. Caractérisation des bitumes routiers par analyse calorimétrique différentielle (ACD). Analyse thermo-optique (ATO), Corrélation entre Chaussées 177: 45-51. 